\title{
Evaluation of Natural Colorants and Their Application on Citrus Fruit as Alternatives to Citrus Red No. 2
}

\author{
Xiuxiu Sun and Elizabeth Baldwin \\ U.S. Department of Agriculture, Agricultural Research Service, U.S. \\ Horticultural Research Laboratory, 2001 South Rock Road, Fort Pierce, \\ FL 34945
}

\author{
Mark Ritenour \\ Indian River Research and Education Center, University of Florida, 2199 \\ South Rock Road, Fort Pierce, FL 34845
}

Anne Plotto and Jinhe Bai ${ }^{1}$

U.S. Department of Agriculture, Agricultural Research Service, U.S. Horticultural Research Laboratory, 2001 South Rock Road, Fort Pierce, FL 34945

\section{Additional index words. annatto, paprika, degreening, waxing}

\begin{abstract}
Warm field temperatures can often result in poor peel color of some citrus varieties, especially early in the harvest season. Under these conditions, Florida oranges, temples, tangelos, and K-Early citrus fruit are allowed to be treated with Citrus Red No.2 dye (CR2) to help produce a more acceptable peel color. Unfortunately, CR2, the commercial colorant used in Florida, has been listed as a group 2B carcinogen by the European Union (EU) and the International Agency for Research on Cancer (IARC). Although not likely dangerous at levels used on citrus, and on a part of the fruit that is not ingested, there is a negative health perception, and thus, a need for natural or food grade alternative colorants to replace CR2 for use on citrus. This research demonstrated that three out of five oil-soluble natural red/orange colorants resulted in peel colors somewhat similar to the industry standard CR2. These three (annatto extract, paprika extract, and paprika oleoresin) were selected for further in vivo studies. The stability of the natural colorants along with CR2 was evaluated by applying them on test papers and then on fresh 'Hamlin' oranges. All natural colorants were found to be easily oxidized and faded when applied on test papers. However, coating the colored surfaces with carnauba wax apparently inhibited oxidation and the subsequent discoloration of the surface. When applying the natural colorants to 'Hamlin' oranges before waxing, the treatments retained the improved color after storage in the dark at $5{ }^{\circ} \mathrm{C}$, simulating cold storage. However, only annatto extract maintained a stable color when subsequently stored in a simulated market condition, at $23^{\circ} \mathrm{C}$ exposed to $300 \mathrm{~lx}$ of standard fluorescent white light.
\end{abstract}

The color of orange peel is a significant attribute influencing consumer product acceptance (Baldwin et al., 2014; Rodrigo et al., 2013). In Florida, early season fruits such as 'Parson Brown' and 'Hamlin' attain full maturity in internal quality during early fall, but often still have green peel (Hall, 2013). Fruit yellowing is due to chlorophyll degradation (Koca et al., 2007), and orange color development depends on accumulation of

Received for publication 26 May 2015. Accepted for publication 27 June 2015 .

Mention of a trademark or proprietary product is for identification only and does not imply a guarantee or warranty of the product by the U.S. Department of Agriculture. The U.S. Department of Agriculture prohibits discrimination in all its programs and activities on the basis of race, color, national origin, gender, religion, age, disability, political beliefs, sexual orientation, and marital or family status.

${ }^{1}$ Corresponding author. E-mail: Jinhe.bai@ars. usda.gov. carotenoids (Kato et al., 2004). As air temperatures fall below $13{ }^{\circ} \mathrm{C}\left(55^{\circ} \mathrm{F}\right)$, chlorophyll degrades to a colorless compound and yellow/orange carotenoids increase resulting in the fruit's characteristic orange appearance (Hall, 2013; Manera et al., 2013).

Fruit that are mature, but with insufficient external color, are degreened to speed color development. This results in the need for degreening by exposing to using low concentrations $(\approx 5 \mathrm{ppm})$ of ethylene, gas which is a natural plant hormone that stimulates the chlorophyll degradation. Mayuoni et al. (2011) evaluated the effects of degreening on internal quality of 'Navel' oranges, 'Star Ruby' grapefruit, and 'Satsuma' mandarins and found no or minor effects on juice total soluble solids content, titratable acidity, juice aroma volatiles, and flavor; concluding that such ethylene treatments likely do not regulate ripening processes or impair internal fruit quality.

For consumer acceptance, fruit harvested before developing sufficient peel color must first be degreened. In Florida, this involves exposing fruit to low concentrations $(\approx 5 \mathrm{ppm})$ of ethylene under warm $\left(29{ }^{\circ} \mathrm{C} ; 85^{\circ} \mathrm{F}\right)$ temperature and high $(\approx 90 \%)$ relative humidity (RH) (Stewart and Wheaton, 1971). These conditions maximize chlorophyll degradation, but inhibit the synthesis of the carotenoids $\beta$-citraurin (red) and cryptoxanthin (orange red) that can resulting in fruit with yellow, rather than orange peel (Hall, 2013). After degreening, poorly colored fruit may be treated with an emulsion containing CR2 to improve fruit peel color (Hall, 2013). In Florida, such treatments are only allowed on oranges, temples, tangelos, and K-Early citrus fruit (Florida Dept. of Citrus, 2014). While approved as safe in the United States, $\mathrm{CR} 2$, has been listed by the IARC and EU as a group 2B carcinogen (IARC, 1987) meaning it is a possible carcinogen, although not a proven risk. Therefore, to dispel potential consumer concerns, a replacement of CR2 with natural or food grade colorants would benefit the Florida citrus industry (Giusti and Wrolstad, 2003; He and Giusti, 2010; Mapari et al., 2006).

Basic requirements for potential alternatives are: 1) red and orange colors that produce an acceptable orange color in treated peel and 2) hydrophobic characteristics so the color remains in the peel and does not transfer to hands, containers, or packaging. In this research, five natural colorants were evaluated that are commercially available and approved as food additives. Their basic physical and chemical properties and commercial use in food industries are described below.

Annatto extracts: a safe and convenient food colorant obtained from achiote (Bixa orellana L.) that has been extensively used to color cheese and other food commodities (Kang et al., 2010). The principal coloring component of annatto is the oil-soluble apocarotenoid 9'-cis bixin, which is the methyl ester of the water-soluble derivative 9'-cis norbixin and accounts for $70 \%$ to $80 \%$ of annatto pigment (Rao et al., 2005; Tummala et al., 2012). Oil-soluble annatto has been used to impart stable color shades in the redorange-yellow range in processed foods such as baked goods, snack foods, and margarine (Preston and Rickard, 1980; Scotter et al., 1998). It was also applied to coconut burfi and double-ka-meeta, and the results showed that the required color shade was obtained by using natural annatto dye (Tummala et al., 2012). The oil-soluble component of annatto dye (bixin) was incorporated into cakes, biscuits, and fried rice; and the bixin loss in these products caused by temperature, microwave, and pressure was evaluated; and the results showed that the oil-soluble annatto formulation can be used in fat-based products, such as butter, cheese, and creams, and the color can readily be used to impart orange-yellow color at low concentration (Rao et al., 2005). Different annatto formulations and their uses in foods have been reviewed showing little work in its application to fruit and vegetable products (Satyanarayana et al., 2003). 
Paprika extracts: the dehydrated and ground fruit of certain varieties of red pepper (Capsicum annuum L.), is one of the most widely used food colorants in the food industry because of its high carotenoid content (de Guevara et al., 2002; Topuz et al., 2009). Its red intensity is the principal characteristic that determines the quality of paprika as a coloring agent (Nagle et al., 1979). Paprika is used to modify the color and flavor of soups, sausage, cheese, snacks, salad dressing, and confectionary products (Nieto-Sandoval et al., 1999). The overall quality of paprika was shown to be stable under normal storage conditions even without the addition of antioxidants (Perez-Galvez et al., 2009). However, a $20 \%$ to $50 \%$ loss of the initial carotenoids and thereby the color of paprika was reported after a prolonged exposure to heat, oxygen, and light (Topuz et al., 2009).

$\beta$-Carotene: a strongly colored red-orange pigment, abundant in plants and fruits, is used as a colorant for juices and beverages (Bauernfeind et al., 1962; Gordon and Bauernfeind, 1982). Its color stability in both direct light and under heated conditions was enhanced with the addition of antioxidants, such as ascorbic acid and rosmarinic acid, to the beverages (Mesnier et al., 2014). $\beta$-carotene has also been used in butter, cheese, and egg yolk products to improve their appearance (Gordon and Bauernfeind, 1982).

Carrot oleoresin: a hexane extraction of dried carrot is made from a special variety of carrot that contains about five times the carotene levels of strains normally found in grocery stores (Barth et al., 1995). It is an orange-red concentrate used mainly for food coloring (Rodriguez-Concepcion and Stange, 2013).

The use of the Commission International de 1' Eclairage (CIE) color system provides a thorough coverage of perceptual attributes necessary to assess the color of food products (Duangmal et al., 2008; Mapari et al., 2006). For example, the color of fungal pigment extracts was analyzed based on the CIE $L^{*} a^{*} b^{*}$ (CIELAB) color characteristics (Mapari et al., 2006), where $L^{*}$ is a measure of lightness, $a^{*}$ as redness/greenness, and $b^{*}$ as yellowness/grayness. The $a^{*} / b^{*}$ ratio serves as an indicator of quantitative development of orange color (Ayers and Tomes, 1966; Bai et al., 2009). A greater $a^{*} / b^{*}$ ratio is a sign of deeper orange color. Therefore, we used CIELAB to evaluate the qualification of each colorant.

The application of wax before marketing is standard practice for fresh market citrus, regardless if color-add is applied, to protect the fruit from water loss and to provide an attractive gloss that increases sales (Bai and Plotto, 2011; Hagenmaier and Baker, 1997). For color-added fruit, wax also inhibits oxidation of colorants, reducing degradation of the colorants (Balaswamy et al., 2006). The objectives of this research were to compare the color characteristics and stability of different natural colorants to find an alternative dye for color-added citrus fruits.

\section{Materials and Methods}

Colorant, solvent, and wax materials. The following five natural food colorants were obtained from private companies: annatto suspension ( $8 \%$ bixin) by Food Ingredient Solutions, LLC (Teterboro, NJ); paprika O/S FANS445 and $\beta$-carotene O/S FANS446 by WILD Flavors Inc. (Erlanger, KY); and Durabrite $^{\circledR}$ carrot oleoresin and Durabrite ${ }^{\circledR}$ paprika oleoresin by Kalsec (Kalamazoo, MI). They were all extracted from plants and the exacted chemical components and purity are proprietary. Citrus Red No. 2 (the control) and wax (carnauba-based Stay-Fresh 2109 , solids content: $24.2 \pm 0.5 \%$ ) were obtained from JBT Corporation (Lakeland, FL). Pure pine oil was purchased from $100 \%$ Pure Essential Oils and Aromatherapy (Mechanicsburg, PA).

Table 1. The CIELAB ${ }^{z}$ results of CR2 and five natural colorants on test paper dried for $3 \mathrm{~h}$ at $23{ }^{\circ} \mathrm{C}$ under $3001 \mathrm{x}$ of standard fluorescent white light.

\begin{tabular}{|c|c|c|c|c|}
\hline Colorant & $L^{* \mathrm{z}}$ & $a^{* z}$ & $b^{* z}$ & $a^{* / b^{* z}}$ \\
\hline$\overline{\mathrm{CR}} 2^{\mathrm{z}}$ & $76.82 b^{y}$ & $31.09 \mathrm{c}$ & $10.52 \mathrm{c}$ & $2.96 \mathrm{a}$ \\
\hline Annatto & $54.30 \mathrm{e}$ & $45.57 \mathrm{a}$ & $39.44 \mathrm{~b}$ & $1.16 \mathrm{~b}$ \\
\hline Paprika & $67.38 \mathrm{~d}$ & $36.98 \mathrm{~b}$ & $56.67 \mathrm{a}$ & $0.65 \mathrm{c}$ \\
\hline$\beta$-Carotene & $87.83 \mathrm{a}$ & $-1.96 \mathrm{~d}$ & $53.14 \mathrm{a}$ & $-0.04 \mathrm{e}$ \\
\hline Carrot oleoresin & $88.13 \mathrm{a}$ & $-5.09 \mathrm{e}$ & $57.35 \mathrm{a}$ & $-0.01 \mathrm{e}$ \\
\hline Paprika oleoresin & $72.76 \mathrm{c}$ & $30.08 \mathrm{c}$ & $55.61 \mathrm{a}$ & $0.54 \mathrm{~d}$ \\
\hline
\end{tabular}

${ }^{\mathrm{z}} L^{*}=$ measure of lightness; $a^{*}=$ redness/greenness; $b^{*}=$ yellowness/grayness; $a^{*} / b^{*}=$ ratio that serves as an indicator of quantitative development of orange color; CIELAB $=$ Commission International de 1 ' Eclairage $L^{*} a^{*} b^{*}$; CR2 $=$ Citrus Red No. 2 .

${ }^{y}$ Mean values followed by different letters within a column indicate significant differences using Duncan test $(P<0.05)$.
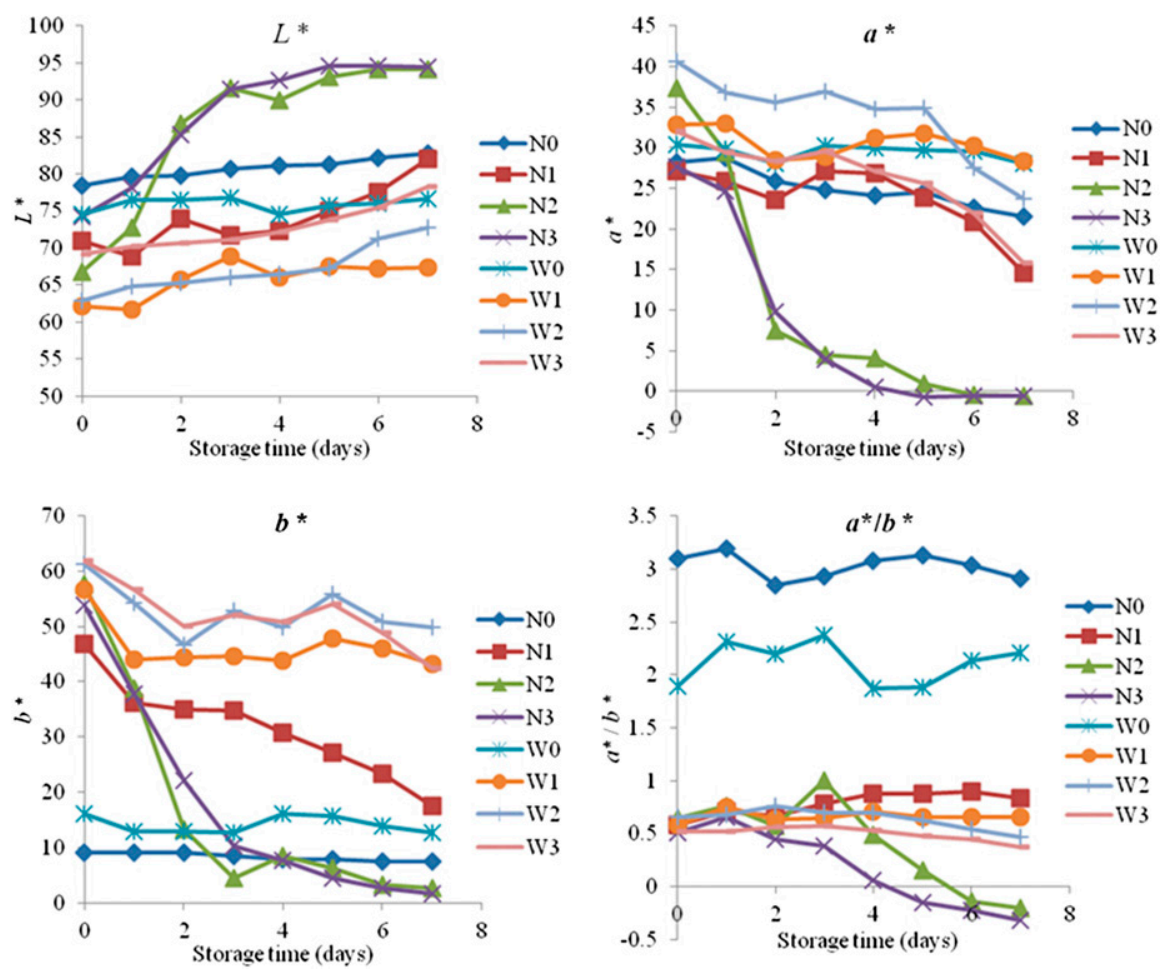

Fig. 1. Changes of color $\left(\mathrm{L}^{*}, \mathrm{a}^{*}, \mathrm{~b}^{*}\right.$, and $\mathrm{a}^{*} / \mathrm{b}^{*}$ ratio) values of four colorants with or without wax covering on test papers over $7 \mathrm{~d}$ of storage at $23^{\circ} \mathrm{C}$ under $300 \mathrm{~lx}$ of standard fluorescent white light. (N0-Citrus Red No. 2, non-waxed; N1-Annatto, non-waxed; N2-Paprika, non-waxed; N3-Paprika oleoresin, nonwaxed; W0- Citrus Red No. 2, waxed; W1-Annatto, waxed; W2-Paprika, waxed; W3-Paprika oleoresin, waxed). 
Fruit degreening, dying and waxing. Orange fruits (Citrus sinensis var. Hamlin) were harvested from the U.S. Department of Agriculture Picos Farm in Fort Pierce, FL. After degreening by exposing the fruit to $2 \mu \mathrm{L} \cdot \mathrm{L}^{-1}$ ethylene at $27{ }^{\circ} \mathrm{C}$ and $95 \%$ to $100 \% \mathrm{RH}$ for $3 \mathrm{~d}, 120$ "yellow" fruits (30 fruit/treatment $\times$ 4 treatments), were selected for the colorant evaluation. Similar to the test paper evaluation, $0.5 \mathrm{~mL}$ of each colorant solution (2 ppm in pine oil) was applied by gloved hands to the fruit surface. For CR2 control, fruit were dyed by following the simulated commercial procedure (Hall, 2013). The dyed fruits were allowed to dry at $23{ }^{\circ} \mathrm{C}$ and $40 \% \mathrm{RH}$ for $3 \mathrm{~h}$, and then carnauba wax, $0.5 \mathrm{~mL}$ per fruit, was applied to the fruits in the same manner as with the dyes. The fruits were dried overnight, and then an initial color measurement was taken. Fruits were stored at $5{ }^{\circ} \mathrm{C}$ in the dark to simulate cold storage, or at $23{ }^{\circ} \mathrm{C}$ under $300 \mathrm{~lx}$ of standard fluorescent white light for up to $14 \mathrm{~d}$ to simulate marketing condition.

Color measurements. CIELAB was used for determining the color coordinates by using a colorimeter (model CR-300, Minolta, Tokyo, Japan). The instrument was calibrated using a white tile. Color was expressed as CIE $L^{*}, a^{*}, b^{*}$, and $a^{*} / b^{*}$ ratio, where $L^{*}$ indicates lightness read from 0 (black) to 100 (white). The positive $a^{*}$ value indicates red color while the negative $a^{*}$ value represents green color. Similarly, positive and negative $b^{*}$ values indicate yellow and blue colors, respectively. A larger $a^{*} / b^{*}$ ratio indicates a darker orange color, and is generally recognized as the preferred color for oranges (Bai et al., 2009). Quantitative discoloration $(\Delta E)$ over time was expressed as: $\Delta E^{*}=$ $\left[\left(\Delta L^{*}\right)^{2}+\left(\Delta a^{*}\right)^{2}+\left(\Delta b^{*}\right)^{2}\right]^{1 / 2}$. The value indicates a total change of lightness, red/ greenness, and yellow/blueness.

Statistical analysis. Analysis of variance (ANOVA) was carried out using SPSS software (version 17). When the $P$ value was less than or equal to 0.05 , the results were considered significant. Separation of means was performed using Duncan test.

\section{Results and Discussion}

Customers prefer fresh oranges with a dark orange peel (Mapari et al., 2009). Preliminary color measurements using CIE$\mathrm{LAB}$ with $\mathrm{CR} 2$ and five natural colorants (annatto, paprika, $\beta$-carotene, carrot oleoresin, and paprika oleoresin) on test papers are shown in Table 1. Carrot oleoresin and $\beta$-carotene were very light with high $L^{*}$ values, and showed yellow to light orange color with negative $a^{*}$, high $b^{*}$, and negative $a^{*} / b^{*}$ values, which were very significantly different from the control (industry standard, CR2). Therefore, they were removed from further evaluation. The other three natural colorants (annatto, paprika, and paprika oleoresin) showed comparable redness with similar or higher $a^{*}$ values to CR2 (Table 1). Although their $b^{*}$ values were much higher and the $a^{*} / b^{*}$ values slightly lower than that of CR2, the general colors were "dark orange," and so were chosen for further evaluation.

Figure 1 shows the stability of CR2 and the natural colorants over time on test papers. CR2 exhibited the most stable color profile on the test paper, regardless if wax was later applied or not (Fig. 1; Table 2). However, rapid discoloration was found after application and storage of paprika-applied colorants, and to a lesser extent with the Annatto colorant, with increasing $L^{*}$ values over time. Addition of wax deepened the color (lower $L^{*}$ values) for all colorants and helped to stabilize the colors. A similar pattern was observed for $a^{*}$ values only in the other direction numerically. Although all colorants declined in $a^{*}$ value over time, especially for the paprika colorants, application of wax increased $a^{*}$ values for all colorants. Only CR2 and waxed CR2 had stable $b^{*}$ values,

and the highest $a^{*} / b^{*}$ ratio (Fig. 1). In general, wax cover maintained higher $a^{*}$, $b^{*}$, and $a^{*} / b^{*}$ values, and lower $L^{*}$ values (Fig. 1), thus prevented discoloration (Table 2). Nevertheless, the natural colorants had lower red/orange color values (Fig. 1, a*/b*) and less stable color (Table 2 ) in comparison with CR2 on the paper test.

Oxygen is one of the important factors resulting in pigment oxidation and color deterioration and discoloration (Gill and Mcginnis, 1995; Valles et al., 2013; Yen et al., 1988). Color fading is thought to occur in a two-step sequence. The first is the dissociation of pigment, which is catalyzed by the presence of oxygen (Tarr and Clingeleffer, 2005), followed by the oxidation of the dissociated pigment (Yen et al., 1988). The effects of oxygen on the discoloration of carotenoid pigments in paprika powders were determined by reversed-phase high-performance liquid

Table 2. Effect of wax cover on discoloration of colorants on test paper after $7 \mathrm{~d}$ of storage at $23{ }^{\circ} \mathrm{C}$ under $300 \mathrm{~lx}$ of standard fluorescent white light.

\begin{tabular}{llccc}
\hline & \multicolumn{4}{c}{ Color change $\left(\Delta E^{*}\right)^{\mathrm{z}}$} \\
\cline { 2 - 5 } Treatment & \multicolumn{1}{c}{ CR2 ${ }^{\mathrm{z}}$} & Annatto & Paprika & Paprika oleoresin \\
\hline Non-waxed & $8.23 \mathrm{Da}^{\mathrm{y}}$ & $33.77 \mathrm{Ca}$ & $72.12 \mathrm{Aa}$ & $62.71 \mathrm{Ba}$ \\
Waxed & $4.94 \mathrm{Cb}$ & $15.05 \mathrm{Bb}$ & $22.74 \mathrm{Ab}$ & $26.89 \mathrm{Ab}$ \\
\hline
\end{tabular}

${ }^{\mathrm{z}} \Delta E^{*}=$ quantitative discoloration $\left\{\Delta E^{*}=\left[\left(\Delta L^{*}\right)^{2}+\left(\Delta a^{*}\right)^{2}+\left(\Delta b^{*}\right)^{2}\right]^{1 / 2}\right\}\left(\right.$ where $L^{*}$ is a measure of lightness, $a^{*}$ as redness/greenness and $b^{*}$ as yellowness/grayness); CR2 $=$ Citrus Red No. 2.

${ }^{y}$ Mean values followed by different uppercase letters within a row and different lowercase letters within a column indicate significant differences using Duncan test and $t$ test, respectively (both at $P<0.05$ level).
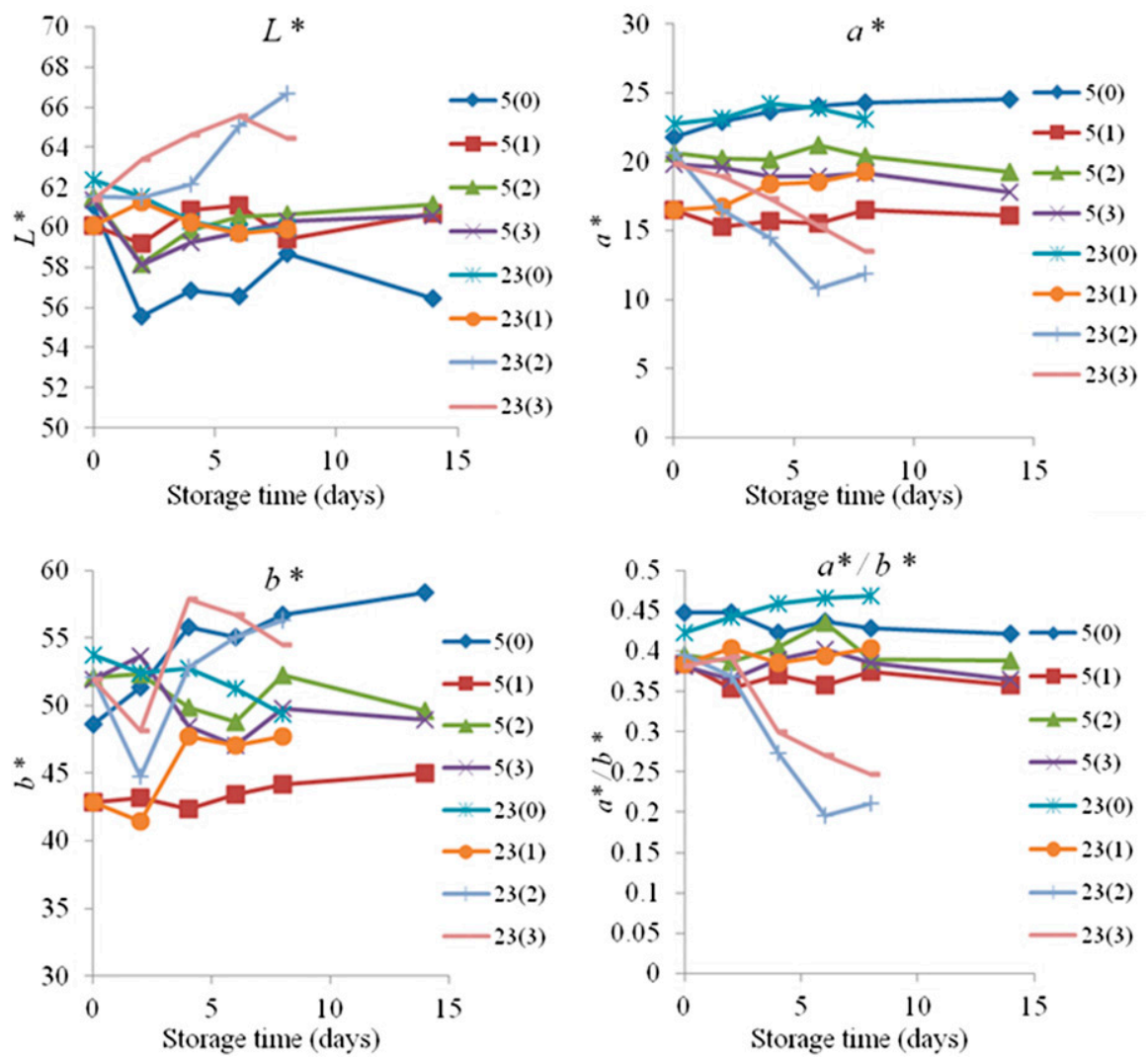

Fig. 2. Changes of color $\left(\mathrm{L}^{*}, \mathrm{a}^{*}, \mathrm{~b}^{*}\right.$, and $\mathrm{a}^{*} / \mathrm{b}^{*}$ ratio) values of four colorants on citrus fruit under the storage conditions as $14 \mathrm{~d}$ at $5{ }^{\circ} \mathrm{C}$ in the dark, or $8 \mathrm{~d}$ at $23{ }^{\circ} \mathrm{C}$ under $300 \mathrm{~lx}$ of standard fluorescent white light. [5(0)- Citrus Red No. 2, $5{ }^{\circ} \mathrm{C}$; 5(1)-Annatto, $5{ }^{\circ} \mathrm{C} ; 5(2)$-Paprika, $5{ }^{\circ} \mathrm{C} ; 5(3)$-Paprika oleoresin, $5{ }^{\circ} \mathrm{C}$; 23(0)- Citrus Red No. 2, $23{ }^{\circ} \mathrm{C}$; 23(1)-Annatto, $23{ }^{\circ} \mathrm{C}$; 23(2)-Paprika, $23{ }^{\circ} \mathrm{C}$; 23(3)-Paprika oleoresin, $23^{\circ} \mathrm{C}$ ]. All fruit were waxed after applying colorant. 
chromatography (RP-HPLC), and the results showed that oxygen significantly increased the overall discoloration of paprika pigments (Morais et al., 2001). The addition of other antioxidants, such as tocopherols, were able to inhibit discoloration of bixin during storage (Balaswamy et al., 2006). It was hypothesized that carnauba wax provides a partial oxygen barrier that protects the colorants from oxidation. Indeed, discoloration of the colorants was significantly decreased (Table 2). The degradation of bixin and carotenoids could be delayed in annatto and paprika respectively by the inhibition of oxidation, which is mainly due to the chemically unstable structure of bixin and polyunsaturated fatty acid profile of the paprika (Perez-Galvez et al., 2009). Bixin is chemically unstable when isolated and converts via isomerization into trans-bixin ( $\beta$-bixin) (Anderson et al., 1997). The concentration of carotenoids in paprika was significantly $(P<0.05)$ decreased by different dying methods, which illustrated the instability of paprika (Topuz et al., 2011).

It has been reported that photo-oxidation of pigments is induced by light (Nasr et al., 1996). In the current experiments, $300 \mathrm{~lx}$ of room lighting was maintained for the treatments at room temperature to hasten discoloration, however, further studies on the effect of different light wavelength, would provide more information. Such a wax coating may inhibit photo-oxidation and subsequent discoloration by partially deflecting light from the bixin in the annatto and carotenoids in the paprika (Donhowe and Fennema, 1993).

The $L^{*}, a^{*}, b^{*}$, and $a^{*} / b^{*}$ values of citrus fruit without color treatment were $70.02 \pm$ $3.52,2.83 \pm 3.49,60.55 \pm 3.41$, and $0.05 \pm$ 0.01 , respectively. To evaluate the effects of colorants on 'Hamlin' orange fruit, colortreated fruits were then coated with a carnauba wax, as is done in commercial packinghouses. The effect of storage conditions on the stability of colorants on the citrus fruit was studied (Figs. 2 and 3; Table 3). During subsequent storage, paprika and paprika oleoresin developed significantly higher $L^{*}$ and lower $a^{*}$ and $a^{*} / b^{*}$ values than CR2 and annatto after $8 \mathrm{~d}$ storage at $20^{\circ} \mathrm{C}$ (Fig. 2). In cold $\left(5^{\circ} \mathrm{C}\right)$ and dark storage, fruits treated with all three natural colorants maintained color throughout the entire storage time, without discoloration (Figs. 2 and 3; Table 3). On the other hand, after fruit were held under lighted conditions at room temperature, fruits colored with paprika and paprika oleoresin decolorized rapidly with rapidly declining $a^{*}$ and $a^{*} / b^{*}$ values (Fig. 2) and increased $\Delta E^{*}$ values (Table 3).

The discoloration of annatto at different temperatures has been reported to be greater at higher temperatures (Balaswamy et al., 2006). Several studies reported on color loss of paprika at different temperatures (de Guevara et al., 2002). In that study, the observed delay in color loss of the powdered paprika was due to the greater quantity of water adsorbed by the paprika samples with increasing RH during storage, which hinders

\section{\begin{tabular}{|l|l|l|l|l|} 
No & \\
colorant & & 5 & 5 \\
\hline
\end{tabular}}

Colorant Day $0 \quad$ Day $14\left(5^{\circ} \mathrm{C}\right) \quad$ Day $8\left(23^{\circ} \mathrm{C}\right)$

$\mathrm{CR} 2$
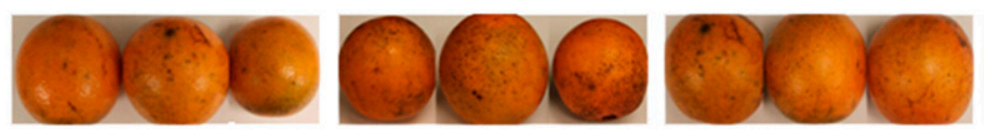

Annatto
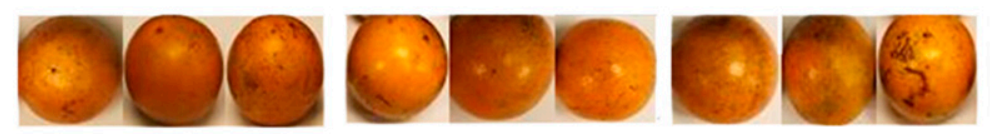

Paprika
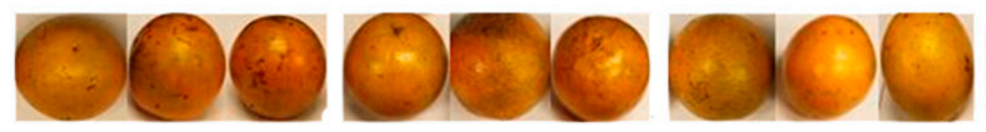

Paprika

oleoresin
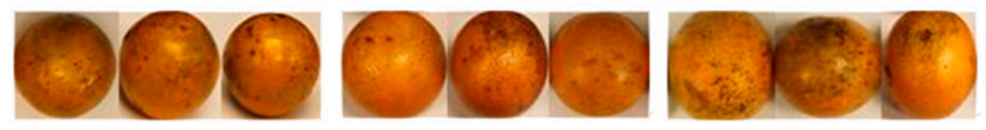

Fig. 3. Appearance of citrus fruit with or without colorants at day 0 , after $14 \mathrm{~d}$ at $5{ }^{\circ} \mathrm{C}$ in the dark, or $8 \mathrm{~d}$ at $23{ }^{\circ} \mathrm{C}$ under $3001 \mathrm{x}$ of standard fluorescent white light. (CR2 = Citrus Red No. 2).

Table 3. Decoloration of orange fruit surface covered by different colorants, coated by carnauba wax and stored for $14 \mathrm{~d}$ at $5{ }^{\circ} \mathrm{C}$ in the dark, or $8 \mathrm{~d}$ at $23{ }^{\circ} \mathrm{C}$ under $300 \mathrm{~lx}$ of standard fluorescent white light.

\begin{tabular}{lcccc}
\hline & \multicolumn{4}{c}{ Color change $\left(\Delta E^{*}\right)^{\mathrm{z}}$} \\
\cline { 2 - 5 } Temperature & $\mathrm{CR}^{\mathrm{z}}$ & Annatto & Paprika & Paprika oleoresin \\
\hline $5{ }^{\circ} \mathrm{C}$ & $5.06 \mathrm{C}^{\mathrm{y}}$ & $6.84 \mathrm{~B}$ & $6.37 \mathrm{~B}$ & $8.48 \mathrm{~A}$ \\
$23{ }^{\circ} \mathrm{C}$ & $7.78 \mathrm{C}$ & $8.54 \mathrm{C}$ & $14.04 \mathrm{~A}$ & $10.18 \mathrm{~B}$ \\
\hline $\mathrm{z} \Delta E^{*}=$ quantitative discoloration $\left\{\Delta E^{*}=\left[\left(\Delta L^{*}\right)^{2}+\left(\Delta a^{*}\right)^{2}+\left(\Delta b^{*}\right)^{2}\right]^{1 / 2}\right\}\left(\right.$ where $L^{*}$ is a measure of
\end{tabular}

${ }^{\mathrm{z}} \Delta E^{*}=$ quantitative discoloration $\left\{\Delta E^{*}=\left[\left(\Delta L^{*}\right)^{2}+\left(\Delta a^{*}\right)^{2}+\left(\Delta b^{*}\right)^{2}\right]^{1 / 2}\right\}$ (where $L^{*}$ is a measure of lightness, $a^{*}$ as redness/greenness and $b^{*}$ as yellowness/grayness); CR2 $=$ Citrus Red No. 2.

${ }^{\mathrm{y}}$ Mean values followed by different letters within a row indicate significant differences using Duncan test $(P<0.05)$.

the access of oxygen to the paprika carotenoids (de Guevara et al., 2002).

Storage time is also an important factor that affects discoloration of pigments. Discoloration of annatto was significantly increased by longer storage time (Rao et al., 2002). The effect of storage time on the discoloration of carotenoid pigments in paprika was determined by RP-HPLC, and showed that storage duration was more important than oxygen or light (Morais et al., 2001).

In conclusion, this study investigated the effect of five oil-soluble natural colorants on citrus fruit peel color. Test paper and fruit evaluation showed that annatto, paprika, and paprika oleoresin resulted in red and orange color when applied to both test paper and 'Hamlin' orange peel, and such treatments were stable under the cold, dark conditions of storage. Although these three colorants improved the 'Hamlin' peel color compared with the untreated control, only annatto was relatively stable under all conditions, including simulated marketing conditions (Fig. 3).
The degradation of these natural colorants is highly associated with oxygen, temperature, light, and storage time. Taken together, the experiments suggest that annatto would be the most successful replacement of CR2 for use as a natural colorant on citrus fruit.

\section{Literature Cited}

Anderson, S.G., M.G. Nair, A. Chandra, and E. Morrison. 1997. Supercritical fluid carbon dioxide extraction of annatto seeds and quantification of trans-bixin by high pressure liquid chromatography. Phytochem. Anal. $8: 247-249$.

Ayers, J.E. and M.L. Tomes. 1966. Effect of 2 Uniform Ripening Genes on Chlorophyll and Carotenoid Contents of Tomato Fruit. P. Amer. Soc. Hort. Sci. 88:550-556.

Bai, J., E.A. Baldwin, A. Plotto, J.A. Manthey, T.G. McCollum, M. Irey, and G. Luzio. 2009. Influence of harvest time on quality of 'Valencia' oranges and juice. Proc. Fla. State Hort. Soc. 122:308-315.

Bai, J. and A. Plotto. 2011. Coatings for fresh fruits and vegetables, p. 185-242. In: E. Baldwin, R. Hagenmaier, and J. Bai (eds.). Edible coatings 
and films to improve food quality. 2nd ed. CRC Press, Boca Raton, FL.

Balaswamy, K., P.G.P. Rao, A. Satyanarayana, and D.G. Rao. 2006. Stability of bixin in annatto oleoresin and dye powder during storage. LwtFood Sci. Technol. 39:952-956.

Baldwin, E., J. Bai, A. Plotto, and M. Ritenour. 2014. Citrus fruit quality assessment: Producer and consumer perspectives. Stewart Posthar. Rev. 10:1-7.

Barth, M.M., C. Zhou, K.M. Kute, and G.A. Rosenthal. 1995. Determination of optimum conditions for supercritical-fluid extraction of carotenoids from carrot (Daucus Carota L). Tissue. J. Agr. Food Chem. 43:2876-2878.

Bauernfeind, J.C., M. Osadca, and R.H. Bunnell. 1962. $\beta$-carotene, color and nutrient for juices and beverages. Food Technol. 16:101-107.

de Guevara, R.G.L., M. Gonzalez, M. GarciaMeseguer, J.M. Nieto, M. Amo, and R. Varon. 2002. Effect of adding natural antioxidants on colour stability of paprika. J. Sci. Food Agr. 82:1061-1069.

Donhowe, I.G. and O. Fennema. 1993. Watervapor and oxygen permeability of wax films. J. Amer. Oil Chem. Soc. 70:867-873.

Duangmal, K., B. Saicheua, and S. Sueeprasan. 2008. Colour evaluation of freeze-dried roselle extract as a natural food colorant in a model system of a drink. Lwt-Food Sci. Technol. 41:1437-1445.

Gill, C.O. and J.C. Mcginnis. 1995. The effects of residual oxygen concentration and temperature on the degradation of the color of beef packaged under oxygen-depleted atmospheres. Meat Sci. 39:387-394.

Giusti, M.M. and R.E. Wrolstad. 2003. Acylated anthocyanins from edible sources and their applications in food systems. Biochem. Eng. J. 14:217-225.

Gordon, H.T. and J.C. Bauernfeind. 1982. Carotenoids as food colorants. Crc. Cr. Rev. Food Sci. 18:59-97.

Hagenmaier, R.D. and R.A. Baker. 1997. Edible coatings from morpholine-free wax microemulsions. J. Agr. Food Chem. 45:349-352.

Hall, D.J. 2013. The color-add process as applied in Florida. Proc. Fla. State Hort. Soc. 126:220 224.

He, J.A. and M.M. Giusti. 2010. Anthocyanins: Natural colorants with health-promoting properties. Annu. Rev. Food Sci. Technol. 1:163187.

Kang, E.J., R.E. Campbell, E. Bastian, and M.A. Drake. 2010. Invited review: Annatto usage and bleaching in dairy foods. J. Dairy Sci. 93:3891-3901.

Kato, M., Y. Ikoma, H. Matsumoto, M. Sugiura, H. Hyodo, and M. Yano. 2004. Accumulation of carotenoids and expression of carotenoid biosynthetic genes during maturation in citrus fruit. Plant Physiol. 134:824-837.

Koca, N., F. Karadeniz, and H.S. Burdurlu. 2007. Effect of $\mathrm{pH}$ on chlorophyll degradation and colour loss in blanched green peas. Food Chem. 100:609-615.

Manera, F.J., J.M. Brotons, A. Conesa, and I. Porras. 2013. Relation between temperature and the beginning of peel color change in grapefruit (Citrus paradisi Macf.). Sci. Hort. 160:292-299.

Mapari, S.A.S., A.S. Meyer, and U. Thrane. 2006. Colorimetric characterization for comparative analysis of fungal pigments and natural food colorants. J. Agr. Food Chem. 54:7027-7035.

Mapari, S.A.S., A.S. Meyer, and U. Thrane. 2009. Photostability of natural orange-red and yellow fungal pigments in liquid food model systems. J. Agr. Food Chem. 57:6253-6261.

Mayuoni, L., Z. Tietel, B.S. Patil, and R. Porat. 2011. Does ethylene degreening affect internal quality of citrus fruit? Postharvest Biol. Technol. 62:50-58.

Mesnier, X., C. Gregory, P. Fanca-Berthon, F. Boukobza, and A. Bily. 2014. Heat and light colour stability of beverages coloured with a natural carotene emulsion: Effect of synthetic versus natural water soluble antioxidants. Food Res. Intl. 65:149-155.

Morais, H., A.C. Ramos, T. Cserhati, and E. Forgacs. 2001. Effects of fluorescent light and vacuum packaging on the rate of decomposition of pigments in paprika (Capsicum annuum) powder determined by reversed-phase high-performance liquid chromatography. J. Chromatography 936:139-144.

Nagle, B.J., B. Villalon, and E.E. Burns. 1979. Color evaluation of selected capsicums. J. Food Sci. 44:416-418.

Nasr, C., K. Vinodgopal, L. Fisher, S. Hotchandani, A.K. Chattopadhyay, and P.V. Kamat. 1996. Environmental photochemistry on semiconductor surfaces. Visible light induced degradation of a textile diazo dye, naphthol blue black, on $\mathrm{TiO}_{2}$ nanoparticles. J. Phys. Chem. 100:8436-8442.

Nieto-Sandoval, J.M., J.A. Fernandez-Lopez, L. Almela, and J.A. Munoz. 1999. Dependence between apparent color and extractable color in paprika. Color Res. Appl. 24:93-97.

Perez-Galvez, A., D. Hornero-Mendez, and M.I. Minguez-Mosquera. 2009. Stability of paprika without supplementary antioxidants during storage under industrial controlled conditions. J. Agr. Food Chem. 57:4718-4723.

Preston, H.D. and M.D. Rickard. 1980. Extraction and chemistry of annatto. Food Chem. 5:47-56.

Rao, P.G.P., T. Jyothirmayi, K. Balaswamy, A. Satyanarayana, and D.G. Rao. 2005. Effect of processing conditions on the stability of annatto
(Bixa orellana L.) dye incorporated into some foods. Lwt-Food Sci. Technol. 38:779-784.

Rao, P.G.P., A. Satyanarayana, and D.G. Rao. 2002. Effect of storage on the stability of water soluble annatto dye formulation in a simulated orange-RTS beverage model system. Lwt-Food Sci. Technol. 35:617-621.

Rodrigo, M.J., B. Alquezar, E. Alos, J. Lado, and L. Zacarias. 2013. Biochemical bases and molecular regulation of pigmentation in the peel of Citrus fruit. Sci. Hort. 163:46-62.

Rodriguez-Concepcion, M. and C. Stange. 2013. Biosynthesis of carotenoids in carrot: An underground story comes to light. Arch. Biochem. Biophys. 539:110-116.

Satyanarayana, A., P.G.P. Rao, and D.G. Rao. 2003. Chemistry, processing and toxicology of annatto (Bixa orellana L.). J. Food Sci. Tech. 40:131-141.

Scotter, M.J., L.A. Wilson, G.P. Appleton, and L. Castle. 1998. Analysis of annatto (Bixa orellana) food coloring formulations. 1. Determination of coloring components and colored thermal degradation products by highperformance liquid chromatography with photodiode array detection. J. Agr. Food Chem. 46:1031-1038.

Stewart, I. and T.A. Wheaton. 1971. Effects of ethylene and temperature on carotenoid pigmentation of citrus peel. Proc. Fla. State Hort. Soc. 84:264-266.

Tarr, C.R. and P.R. Clingeleffer. 2005. Use of an oxygen absorber for disinfestation of consumer packages of dried vine fruit and its effect on fruit colour. J. Stored Prod. Res. 41:77-89.

Topuz, A., C. Dincer, K.S. Ozdemir, H. Feng, and M. Kushad. 2011. Influence of different drying methods on carotenoids and capsaicinoids of paprika (Cv., Jalapeno). Food Chem. 129:860865.

Topuz, A., H. Feng, and M. Kushad. 2009. The effect of drying method and storage on color characteristics of paprika. Lwt-Food Sci. Technol. 42:1667-1673.

Tummala, J., P.R. Pamidighantam, P.M. Babu, and S. Akula. 2012. Selection and application of annatto (Bixa orellana L.) dye formulations in some traditional sweetmeat and savoury products. J. Sci. Ind. Res. 71:788-793.

Valles, M., M. Mercade, F. Duran-Sindreu, J.L. Bourdelande, and M. Roig. 2013. Influence of light and oxygen on the color stability of five calcium silicate-based materials. J. Endod. 39:525-528.

Yen, J.R., R.B. Brown, R.L. Dick, and J.C. Acton. 1988. Oxygen transmission rate of packaging films and light exposure effects on the color stability of vacuum-packaged dry salami. J. Food Sci. 53:1043-1046. 